\title{
AGRESSIVIDADE INFANTIL NO AMBIENTE ESCOLAR: CONCEPÇÕES E ATITUDES DO PROFESSOR
}

\author{
Maria Abigail de Souza \\ Rebeca Eugênia Fernandes de Castro
}

\begin{abstract}
RESUMO. Ao se abordar o tema da agressividade infantil no ambiente escolar é preciso considerar a participação dos envolvidos neste fenômeno: pais, crianças e professores. Tal abordagem vem sendo conduzida em projeto de pesquisa mais amplo, do qual o presente estudo representa um recorte, ao enfocar apenas o ponto de vista dos professores. O objetivo é analisar as concepções e atitudes relacionadas à expressão da agressividade infantil na escola. Realizou-se uma avaliação qualitativa, por meio de entrevistas individuais semidirigidas com 15 professores de uma escola pública da periferia de São Paulo. As atitudes mais citadas como agressivas envolvem rebeldia e agressão física entre alunos, sendo esta última a queixa que mais motiva o encaminhamento para ludoterapia. Em relação às estratégias de manejo, predominam atitudes envolvendo diálogo e compreensão. Os dados sugerem que subsiste preocupação do professor com as crianças, o que desperta nelas a esperança de obter atenção e cuidado.
\end{abstract}

Palavras-chave: alunos agressivos, professores, ludoterapia.

\section{CHILDREN'S AGGRESSIVENESS AT SCHOOL: TEACHER'S CONCEPTIONS AND ATTITUDES}

\begin{abstract}
The participation of all people, parents, children and teachers, involved in children aggressiveness in the school environment is needed to study the phenomenon. This approach has been undertaken through a larger research, including current study, which focuses on the teacher's point of view. Teachers' conceptions and attitudes about children aggressive expressions in school are investigated. A qualitative assessment was undertaken. It comprised individual semidirected interviews with 15 teachers of a public school in a low-income population suburb in São Paulo SP Brazil. Most cited aggressive attitudes include revolt and physical aggression among students. The latter complaint is the main reason that motivates teachers to send children to play-therapy. Conflict administration strategies involve dialogue and comprehension. Data suggest that concern by the teacher on children still exists in whom they hope to obtain attention and care.
\end{abstract}

Key words: Aggressive children, teachers, play-therapy.

\section{AGRESIVIDAD INFANTIL EN EL AMBIENTE ESCOLAR: CONCEPCIONES Y ACTITUDES DEL PROFESOR}

\begin{abstract}
RESUMEN. Al abordarse la agresividad infantil en el ambiente escolar, es necesario considerar la participación de los envolvidos en este fenómeno: padres, niños, profesores. Este abordaje ha sido conducido en un proyecto de investigación más amplio, del cual este estudio representa un recorte, al focalizar el punto de vista del profesor. El objetivo es analizar concepciones y actitudes relacionadas a la agresividad infantil en la escuela. Se ha realizado una evaluación cualitativa, por medio de entrevistas individuales semi dirigidas con 15 profesores de una escuela pública de la periferia de Sao Paulo. Las actitudes agresivas más citadas son rebeldía y agresión física entre alumnos, siendo esta última la queja que más motiva la indicación para ludo terapia. En las estrategias de conducción predominan actitudes envolviendo diálogo y comprensión. Los datos sugieren que subsiste preocupación del profesor con los niños, lo que despierta en ellos la esperanza de lograr atención y cuidado.
\end{abstract}

Palabras-clave: Alumnos agresivos, profesores, ludo terapia.

O presente trabalho surgiu a partir da experiência de atendimento psicoterápico a crianças agressivas realizado no ambiente escolar, e faz parte de um projeto de pesquisa mais amplo, de caráter preventivo.

* Professora Livre-Docente, Departamento de Psicologia Clínica, Universidade de São Paulo-USP.

\# Mestre em Psicologia Clínica. 
Este atendimento, oferecido de 1997 a 2007, procurava proporcionar um trabalho ludoterápico a crianças que apresentavam queixa de agressividade e cujas famílias não tinham condições de levá-las à Clinica-Escola da USP ou a outros serviços gratuitos de atendimento psicoterapêutico. Assim, a ludoterapia realizava-se na própria escola, em um espaço reservado exclusivamente para esta finalidade.

Neste contexto, a queixa inicial de agressividade sempre partia da coordenação e/ou dos professores das crianças, sendo indicadas aquelas que constantemente se envolviam em brigas corporais com os colegas, desrespeitando os adultos da escola, manifestando grande agitação e não realizando as tarefas escolares.

Considerando-se a necessidade de conhecer a história da criança, a fim de obter elementos sobre seu desenvolvimento emocional, o processo terapêutico incluía uma entrevista inicial com os responsáveis, bem como entrevistas de acompanhamento ao final de cada semestre letivo. O mesmo procedimento era adotado com os professores da criança, uma vez que, antes mesmo da família, eles haviam sido os primeiros a expressar preocupação e mal-estar em função do comportamento infantil. Neste contato com os professores constatou-se a importância de compreender melhor a queixa, investigando as concepções e atitudes diante das manifestações de agressividade das crianças, visto que a postura deles parecia influenciar a evolução do processo psicoterapêutico.

\section{ORIGENS DA AGRESSIVIDADE INFANTIL}

A existência de impulsos agressivos é inerente à constituição do ser humano, como esclarecem os psicanalistas Klein (1970) e Winnicott (1939/1987a). Segundo esses autores, o modo e as razões de a agressividade se destacar no funcionamento psíquico gerando a delinquiência e o comportamento anti-social na vida adulta - constituem um processo que se inicia precocemente e está estreitamente ligado ao desenvolvimento infantil.

Para Klein (1970), a criança começa bem cedo a vivenciar os conflitos com suas pulsões destrutivas, já no final do primeiro ano de vida e início do segundo. Trata-se de uma experiência dolorosa, marcada por tensão, angústia, culpa e medo. Quanto menor a capacidade da criança de tolerar estes sentimentos, maior a necessidade de bani-los de seu mundo interno, projetando-os para fora. Com isso, o ambiente passa a representar um perigo em potencial, já que se torna o depositário de sentimentos fortes e destrutivos da criança, despertando-lhe mais angústia. A autora explica que o comportamento anti-social viria aplacar esta angústia, pois as represálias sofridas em função da agressividade confirmariam a fantasia de um mundo perigosamente mau, e as punições também minimizariam a ansiedade e a culpa sentidas inconscientemente pelo fato de provocarem sentimentos ruins no mundo externo. Klein (1970) afirma que a capacidade de suportar ansiedade e tolerar sentimentos de culpa, a etapa de desenvolvimento em que fatos traumáticos ocorreram e a história de vida constituem os fatores que diferenciam a criança "normal" daquela mais predisposta à personalidade anti-social.

Winnicott (1939/1987a), por sua vez, aprofunda as observações kleinianas, salientando a importância do ambiente para permitir a expressão e transformação da agressividade infantil. Partindo do princípio de que a agressividade, no início da vida, não traz consigo a intenção de destruir, o autor enfatiza a função da mãe na criação de condições para que a criança possa tolerar a ansiedade e a culpa provenientes das pulsões destrutivas. Tais condições são possíveis na medida em que a mãe se mostre uma presença confiável, disponível, tolerante e constante, ou seja, como alguém que cuida da criança suprindo-a não apenas de alimentação e conforto, mas também de segurança emocional. Quando, ao contrário, não há condições para a formação de um vínculo seguro e estável com a figura materna, a criança não consegue alcançar uma organização interna madura o suficiente para integrar a própria destrutividade, necessitando cada vez mais da continência ambiental a fim de controlar seus impulsos.

Para Winnicott (1956/1987b), as crianças que manifestam tendência anti-social são aquelas cujo desenvolvimento vinha caminhando bem até que, por algum motivo, foi perdido algo que nutria sua segurança psíquica. A agressividade constitui, então, um pedido, uma reivindicação ao ambiente para o retorno ao ponto em que houve falha no desenvolvimento, a fim de dar curso ao que foi interrompido. Seja na mentira, seja no furto ou na depredação, a manifestação da tendência anti-social revela a necessidade de reconhecimento externo daquilo que faltou e do suprimento dessa falta, vivida como experiência dolorosa. Deve-se considerar que 
uma criança agressiva não o é o tempo inteiro. Seus impulsos de destrutividade surgem nos períodos de esperança, ou seja, quando o meio lhe transmite elementos de confiabilidade. Por isso mesmo Winnicott (1956/1987b) aponta a escola como ambiente propício à manifestação agressiva, nos casos em que: 1) a criança não encontrou continência necessária aos seus impulsos no seio familiar e 2) apresenta esperança e confiança de que a escola possa cumprir essa função.

Esta esperança, que surge de forma inadequada através de comportamentos agressivos destrutivos, revela o que Winnicott (1956/1987b) aponta como um dos aspectos do "valor de incômodo da criança antisocial" (p. 132). No ambiente escolar, o valor de incômodo pode corresponder a um conjunto de elementos como o desafio às normas, o baixo desempenho acadêmico, o comportamento agitado e a perturbação do ambiente. Isto parece se coadunar com as afirmações de Katz (1992), psicoterapeuta americana especializada em atendimento a crianças agressivas, sobre o fato de que estas crianças preferem brincadeiras envolvendo grande atividade motora, como decorrência da dificuldade de engajamento em jogos simbólicos. Kernberg e Chazam (1993), especialistas em psicoterapia infantil, registram que as crianças com transtorno de conduta apresentam déficits em nível egóico nas seguintes áreas: atenção, controle de impulso, julgamento, modulação do afeto, linguagem e tolerância à frustração. Observa-se que estes déficits constituem importantes aspectos que concorrem para prejudicar o desempenho escolar.

\section{AGRESSIVIDADE INFANTIL NA ESCOLA}

A pesquisa de Freller (1993) reafirma o papel da escola como provedora de continência para limitar e controlar a agressividade infantil. Seu estudo analisa a história de sete crianças encaminhadas ao psicólogo escolar com a queixa de indisciplina, as quais eram consideradas desobedientes ou imaturas, com baixo desempenho escolar e objeto de freqüentes reclamações de comportamento. Entrevistando não apenas as crianças, mas também seus pais e professores, a pesquisadora constatou que o comportamento dispersivo ou agitado destes alunos expressava rupturas vividas precocemente e reeditadas no ambiente escolar. Segundo a pesquisadora, estas crianças mantinham a esperança de que a instituição pudesse ir ao encontro de suas necessidades de atenção e cuidados, porém este "pedido" acabava não sendo reconhecido ou compreendido pelos educadores.

Souza, Soldatelli e Lopes (1997), investigando o psicodinamismo familiar de crianças agressivas, comprovam os efeitos da privação emocional em meninos com queixa de agressividade no ambiente escolar. As autoras demonstram que estas crianças apresentam-se de forma agressiva na escola com o fim de vivenciar aquilo que seus lares não puderam oferecer: a possibilidade de uma expressão afetiva mais espontânea e o estabelecimento de limites.

Kupfer (1998) analisa aspectos da cultura para afirmar que o professor brasileiro não encontra mais uma rede de sustentação simbólica que lhe assegure o suporte da autoridade no exercício da profissão. Sugere, assim, que a agressividade na escola seja uma reação à falta de limites simbólicos essenciais para o aprendizado e crescimento humano, podendo apresentar-se sob três diferentes naturezas: 1) imaginária, dirigida ao professor, na forma de pequenos ataques que o desqualificam, numa agressividade miúda e cotidiana; 2) real, portanto próxima da ação psicótica, em que não há sentido para os atos, a exemplo da depredação pura e simples; e 3) simbólica, no sentido de restaurar a figura de autoridade perdida, como acontece em contextos escolares dirigidos pela lei de traficantes.

Esta agressividade, que se traduz em ataques rotineiros à instituição escolar, seus usuários e seus representantes (professores e funcionários), tem sido denominada de incivilidade (Charlot \& Émin, 1997; Debarbieux, 1998, 1999), justamente pelo fato de caracterizar-se por afrontas banais e aparentemente gratuitas, deteriorando as relações nesse ambiente. Além disso, são expressões constatadas em idade cada vez mais precoce. Tremblay (2000), analisando estudos longitudinais sobre a agressividade infantil, observa que o aprendizado do comportamento de agressão física tem início nos anos pré-escolares, sugerindo intervenção preventiva nesse período. Charlot (2002) comenta que os registros de agressividade têm envolvido alunos a partir de oito anos de idade.

\section{CONCEPÇÕES E ATITUDES DOS PROFESSORES RELACIONADAS À AGRESSIVIDADE INFANTIL}

O que os professores consideram agressivo? Muitos estudos têm enfocado esta pergunta, revelando quais manifestações constituem queixa entre os professores, trazendo-lhes sofrimento. Os resultados demonstram que as manifestações mais citadas pelos docentes, registradas nas pesquisas com este público, 
constituem as agressões físicas e verbais entre alunos (Anser, Joly \& Vendramini, 2003; Batista \& Pinto, 1999; Candau, 1999; Carlotto \& Palazzo, 2006; Laterman, 2002; Ristum \& Bastos, 2004) e as agressões verbais dirigidas diretamente aos professores (Batista \& Pinto, 1999; Carlotto, 2002; Hastings \& Bham, 2003; Lopes, 2000; Meleiro, 2002). São poucos os estudos que enfocam a implicação dos professores nos conflitos observados em classe, bem como a avaliação do manejo destas situações.

Nessa perspectiva, destaca-se o trabalho de Tricoli (2002), que avalia o estresse dos professores como resultado de uma postura agressiva em sala de aula. A autora afirma que docentes agressivos, que gritam para colocar ordem na classe, inspiram comportamentos semelhantes em seus alunos. Assim, após um período de convivência, os alunos assumem atitudes tão agressivas quanto aquelas adotadas por seus professores ou apresentam comportamentos mais retraídos, em virtude do medo de punição.

Pesquisa realizada por Royer (2003) revela que os docentes mostram-se inábeis perante a emergência de comportamentos problemáticos, recorrendo costumeiramente a uma atitude punitiva, "parecendo não saber como intervir de forma adequada" (p. 60). Demonstra, ainda, que muitos professores tendem a recorrer ao álcool ou a determinadas drogas na tentativa de minimizar o sofrimento, e que há uma grande procura por serviços terapêuticos.

Para Silva (2006), a exemplo dos alunos considerados agressivos, os professores também manifestam sua agressividade através de diferentes formas de evasão, com seu desinteresse pelo trabalho, acomodação, mudança de escola, abandono do emprego e até da profissão.

Desse modo, constata-se que, se por um lado há convergência na percepção do que é vivenciado como expressão agressiva pelos docentes, por outro também é possível observar certa impotência e despreparo em relação ao manejo destas manifestações. A agressividade infantil, ainda que reflita a esperança de suprir necessidades muito precoces, também provoca hostilidade, desejos de retaliação ou mesmo de evasão por parte dos professores, o que demanda um aprofundamento sobre as atitudes que os docentes assumem em sala de aula ao interpretarem as atitudes infantis como agressivas.

\section{OBJETIVO}

Este trabalho tem por objetivo analisar concepções e atitudes de professores quanto à queixa de agressividade infantil, observando não apenas as manifestações consideradas agressivas, mas também as estratégias adotadas para manejar os conflitos e as formas de controle consideradas ideais.

\section{MÉTODO}

Participaram desta experiência 15 professores (um do sexo masculino e 14 do sexo feminino) de uma escola pública de Ensino Fundamental da periferia de São Paulo, os quais tiveram alunos encaminhados para o atendimento psicoterapêutico oferecido pelo projeto. Estes professores foram submetidos a uma entrevista semidirigida, realizada individualmente, cujos itens podem ser visualizados nas tabelas 1 e 2 . Os dados coletados nas entrevistas foram categorizados sob dois pontos de vista: 1) a concepção dos professores sobre a agressividade infantil no ambiente escolar, as estratégias de manejo adotadas e o papel da escola na sua prevenção; 2) a avaliação dos professores sobre 20 crianças encaminhadas para atendimento em função da queixa de agressividade, ressaltando-se que alguns deles encaminharam mais de uma criança.

\section{RESULTADOS E DISCUSSÃO}

\section{Dados fornecidos pelos docentes em situação de entrevista}

Os 15 professores entrevistados atuavam basicamente nas primeiras séries do ensino fundamental $(67 \%)$ e contavam, predominantemente, com uma experiência de ensino que variava de 2 a 10 anos $(33 \%)$ e de 10 a 20 anos (33\%). À exceção de um docente, todos os demais $(93 \%)$ relataram experiências de enfrentar comportamentos agressivos em sala de aula.

A Tabela 1 sintetiza as atitudes consideradas pelos 15 professores como agressivas dentro de classe, assim como as providências adotadas diante destas situações e as concepções sobre o que seria um aluno bem-adaptado, um professor bem-adaptado e um professor agressivo. A expressão "bem adaptado" foi escolhida a partir da experiência-piloto de aproximação com os professores, ao se constatar a freqüente menção a este termo quando o educador desejava transmitir a idéia de convivência ideal. É esta conotação que se encontra na tabela 1 , ainda que se saiba que o termo pode ser compreendido em analogia com o conceito de inspiração piagetiana, que traduz a conjunção dos processos de assimilação e acomodação na aprendizagem. 
Tabela 1. Respostas dos Professores Sobre a Agressividade em Sala de Aula, Estratégias de Manejo e Condutas Bem Adaptadas do Professor e do Aluno.

\begin{tabular}{|c|c|c|c|}
\hline Categorias & Respostas & $\mathbf{N}$ & $\%$ \\
\hline \multirow{6}{*}{ Atitudes agressivas } & Rebeldia com professor & 13 & 87 \\
\hline & Agressão física entre alunos & 13 & 87 \\
\hline & Agressão verbal entre alunos & 4 & 27 \\
\hline & Não cumprimento dos deveres escolares & 3 & 20 \\
\hline & Desatenção & 2 & 13 \\
\hline & Inquietação & 1 & 7 \\
\hline \multirow{5}{*}{$\begin{array}{l}\text { Estratégias de manejo } \\
\text { adotadas }\end{array}$} & Compreensivo, tenta resolver por si mesmo, evita diretoria & 7 & 47 \\
\hline & Compreensivo, chama a família & 4 & 27 \\
\hline & Tenta resolver, conversar, mas manda para a diretoria & 3 & 20 \\
\hline & Tenta mudança de sala ou escola & 3 & 20 \\
\hline & Deixa que os alunos se entendam & 1 & 7 \\
\hline \multirow{3}{*}{$\begin{array}{l}\text { Caract. do aluno bem } \\
\text { adaptado }\end{array}$} & Respeito ao professor & 8 & 53 \\
\hline & Faz deveres & 8 & 53 \\
\hline & Interessado & 4 & 27 \\
\hline \multirow{4}{*}{$\begin{array}{l}\text { Caract. do professor } \\
\text { bem adaptado }\end{array}$} & Respeito ao indivíduo (sociabilidade) & 6 & 40 \\
\hline & Compreensivo, resolve problemas, tem paciência com as crianças (afetividade) & 5 & 33 \\
\hline & Estimula a participação dos alunos (ênfase no desempenho intelectual) & 5 & 33 \\
\hline & Não sei & 1 & 7 \\
\hline \multirow{4}{*}{$\begin{array}{l}\text { Caract. do professor } \\
\text { agressivo }\end{array}$} & Agride os alunos verbalmente & 8 & 53 \\
\hline & Postura egoísta & 6 & 40 \\
\hline & Agride os alunos fisicamente & 5 & 33 \\
\hline & Postura intolerante & 1 & 7 \\
\hline
\end{tabular}

Observa-se que os professores sentem-se muito mais incomodados com a agressividade motora entre alunos e o desrespeito ao professor do que com a agitação do aluno ou a não-realização de tarefas. Este dado é corroborado pelos resultados obtidos em outras pesquisas (Batista \& Pinto, 1999; Candau, 1999; Carlotto \& Palazzo, 2006; Hastings \& Bham, 2003; Laterman, 2002; Ristum \& Bastos, 2004).

Em relação às estratégias de manejo da agressividade do aluno, nota-se que a maioria tenta compreender, resolver por si mesmo (47\%) ou ser compreensivo e convocar a família (27\%). Outras medidas são adotadas, como o encaminhamento à diretoria $(20 \%)$ ou mudança de sala (20\%). No entanto, as respostas predominantes são aquelas que envolvem a compreensão, a esperança de continência e o acolhimento em relação à atitude agressiva, o que diverge dos resultados apontados pelos estudos com professores, em que os sentimentos de hostilidade e impotência constituem os aspectos preponderantes (Anser, Joly \& Vendramini, 2003; Aquino, 1999; Tricoli, 2002).

Diante deste resultado pode-se pensar que as manifestações agressivas das crianças despertam nos professores não apenas sentimentos dolorosos ou destrutivos, mas também preocupações, o que reflete uma atitude ambivalente. Parece ser justamente na percepção desta ambivalência que os alunos podem sentir-se parcialmente cuidados. Se as crianças só percebessem a polaridade relativa ao ódio nas atitudes dos professores, provavelmente não buscariam mais obter reconhecimento externo com seu comportamento agressivo, pois, conforme Winnicott (1939/1987a), o sintoma agressividade também pode ser visto como uma manifestação positiva de esperança, pois na falta dela viria a depressão. Neste caso, seria razoável pensar que os professores estejam alimentando a esperança destes alunos de encontrar continência no ambiente escolar.

Esta hipótese é corroborada na análise das percepções sobre o "professor bem-adaptado", pois esta concepção apresentada pelos docentes também contempla os requisitos de compreensão, respeito e estímulo à participação, refletindo a preocupação com os alunos tanto em relação aos aspectos intelectuais quanto aos socioafetivos. Essa concepção de "professor bem-adaptado", por menos que se concretize na prática, permeia as expectativas dos professores como um ideal de realização profissional. Por isso mesmo, pode trazer elementos que devem circular entre o dito e o não-dito na relação professoraluno, delineando sinais que são captados como esperança. Destaque-se ainda que a visão do "professor bem-adaptado" se coaduna com a do "aluno bem-adaptado", dando prioridade a dois requisitos que sustentam o enquadre da sala de aula: respeito às relações e cumprimento de tarefas. Deve-se lembrar que todo enquadre - seja ele explícito ou não 
- reflete parâmetros e limites à atuação dos participantes. O enquadre caracteriza tudo o que é constante, desde o espaço até as regras de convivência. É essa constância que faz do enquadre fator de reasseguramento. A aula, a escola e a relação com o professor podem compor aquilo que se pode chamar de mundo conhecido, portanto, fator de segurança propício à manifestação de reivindicações e ao estabelecimento de limites.

A agressão verbal dirigida aos alunos (53\%) e a postura egoísta $(40 \%)$ predominam na concepção de "professor agressivo". Deve-se destacar que esta postura egoísta representava a falta de compromisso com o exercício da função docente, na medida em que significava não estar presente nas aulas, não oferecer conteúdo e não ser dedicado. Aparentemente, estes professores apresentavam uma noção intuitiva de que esta negligência no exercício profissional equivaleria a uma atitude agressiva, que falha no provimento de um ambiente bom e reassegurador. Mais uma vez, pode-se fazer uma analogia com a relação "mãe-bebê" postulada por Winnicott (1939/1987a), a qual teria um efeito destrutivo para a criança caso não seja oferecido o alimento e a tranqüilidade necessária ao desenvolvimento.

Estes mesmos professores tiveram a oportunidade de encaminhar os meninos para atendimento ludoterápico. Ao justificarem o encaminhamento do aluno sob sua responsabilidade que consideravam "agressivo", apresentaram com maior freqüência as seguintes queixas: a dificuldade de realizar tarefas escolares, as brigas freqüentes e agressões físicas entre colegas, e a agitação, como se pode observar na Figura
1. São queixas freqüentemente encontradas na literatura sobre meninos agressivos (Katz, 1992; Kernberg \& Chazan, 1993), que confirmam seu "valor de incômodo" no ambiente escolar, porquanto tais comportamentos rompem com as regras do enquadre em sala de aula.

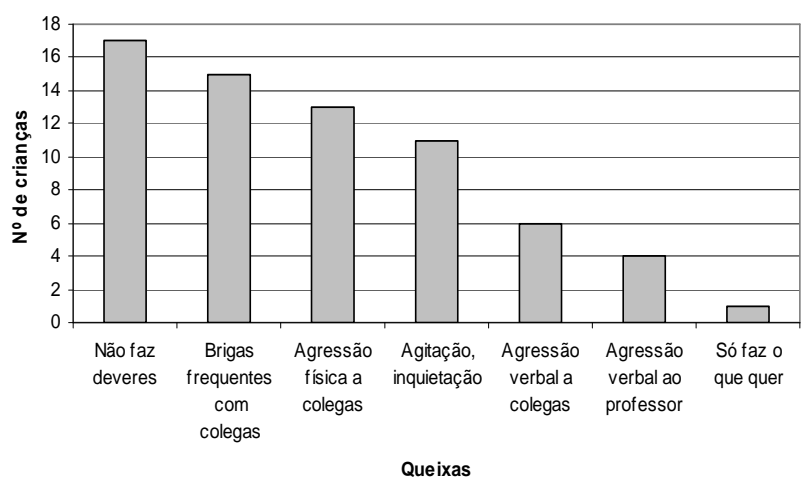

Figura 1. Queixas Relatadas Pelos Professores em Relação a 20 Crianças Consideradas Agressivas

Quanto às estratégias adotadas, conforme a Tabela 2, todos os professores afirmaram ter conversado com a criança sobre a queixa de agressividade e, em $65 \%$ dos casos, chamaram os pais. A família não compareceu à escola em $25 \%$ dos casos de convocação, e em $40 \%$ sua participação não trouxe mudanças para o comportamento da criança. É preciso salientar que os professores costumavam acompanhar a vida da criança em $60 \%$ dos casos, sabendo como estava a família através do aluno ou, como geralmente acontecia, por meio de queixas trazidas pela mãe.

Tabela 2. Avaliação dos professores sobre a queixa de agressividade de 20 crianças

\begin{tabular}{|c|c|c|c|}
\hline Categorias & Respostas & $\mathbf{N}$ & $\%$ \\
\hline \multirow{4}{*}{ Motivo da queixa } & Problemas em casa, família & 15 & 75 \\
\hline & Necessidade de chamar atenção para si & 2 & 10 \\
\hline & Não sabe & 2 & 10 \\
\hline & Perda da avó, piora da saúde do pai & 1 & 5 \\
\hline \multirow{5}{*}{$\begin{array}{l}\text { O que poderia modificar o } \\
\text { comportamento }\end{array}$} & Atenção individualizada ao aluno & 10 & 50 \\
\hline & Conversar com aluno, mãe, família & 5 & 25 \\
\hline & Passar mais tempo na escola & 1 & 5 \\
\hline & Não sabe, já fez o que pôde & 2 & 10 \\
\hline & Não sabe & 2 & 10 \\
\hline \multirow{4}{*}{$\begin{array}{l}\text { Contribuição do professor na } \\
\text { mudança da criança }\end{array}$} & Está tentando o que sugere & 14 & 70 \\
\hline & Não tem paciência ou capacitação & 3 & 15 \\
\hline & Não tem tempo & 2 & 10 \\
\hline & Não sabe & 1 & 5 \\
\hline \multirow{3}{*}{ Contribuição da escola } & Atividades, oficinas, material & 5 & 25 \\
\hline & Não se omitir ou expulsar, implicar pais & 6 & 30 \\
\hline & Não sabe & 9 & 45 \\
\hline
\end{tabular}

Para $75 \%$ das crianças avaliadas, os docentes atribuíram a queixa de agressividade a problemas em casa ou na família. Apenas no caso de duas crianças os professores não souberam a que atribuir o motivo da 
queixa, evidenciando quanto procuravam considerar o contexto dos alunos, suas necessidades afetivas e seus problemas atuais ao efetuarem essa avaliação. Deve-se salientar que na experiência de trabalho com os professores observava-se quanto estes eram solicitados a ouvir a família, com todas as suas queixas. É raro que os responsáveis por alunos que apresentam problemas de comportamento apareçam espontaneamente para conversar com o professor. Entretanto, quando comparecem às convocações, depositam no docente carga expressiva de angústia, despertando o sentimento tentador de "fazer alguma coisa". Tendo em vista que nem sempre é viável modificar certas contingências, este sentimento é desencadeador de sentimento de impotência e frustração. Para amenizar esta sensação de fracasso procurava-se sinalizar aos professores a dificuldade que eles teriam ao assumir a dupla função de educador e psicólogo junto a essas crianças e suas famílias, ressaltando assim a contribuição específica de cada profissional.

Sobre o que poderia modificar o comportamento agressivo, metade das respostas apontou no sentido da atenção individualizada ao aluno, evidenciando uma percepção de que as dificuldades apresentadas pelas crianças consideradas agressivas exigem maior disponibilidade e manejo específico, bem como a impossibilidade de fazê-lo em sala de aula, juntamente com o restante da turma. Esta resposta é seguida pela conversa com o aluno e família $(25 \%$ do total de respostas), sugerindo a compreensão da importância da implicação familiar.

Do ponto de vista da contribuição do professor para a mudança da criança, os professores afirmaram estar, na maioria das vezes $(70 \%)$, aplicando o que sugerem. O registro da falta de tempo (10\%), de paciência ou capacitação $(15 \%)$ parece explicitar o desgaste, o cansaço e a impotência mencionados na literatura (Camps \& Vaisberg, 2003; Collingridge, 2004; Lopes, 2000; Souza, 2001).

Sobre a contribuição da escola, nota-se que mais da metade $(55 \%)$ das respostas indica o potencial de ajuda que é atribuído à instituição, o que fortalece, mais uma vez, o elemento de esperança captado pelas crianças agressivas no ambiente escolar.

\section{Exemplos de repercussão do atendimento à criança sobre as atitudes do professor}

A experiência de acompanhamento a professores cujos alunos são atendidos em ludoterapia fornece alguns indícios de seu engajamento, apesar de todas as dificuldades vivenciadas.

Os contatos com os professores, realizados no mínimo a cada início e final de semestre, tinham como objetivo conversar sobre a criança atendida, principalmente para ouvir as observações a respeito de seu desenvolvimento e a apreciação sobre os efeitos da intervenção em andamento. Abria-se a possibilidade de o professor procurar o terapeuta para conversar e tirar dúvidas se assim o desejasse, mas esta conversa seria sempre comunicada ao aluno, que teria a liberdade de escolher se estaria presente a ela ou não. Vale assinalar que as crianças nunca desejavam participar destas conversas. Era dito ao professor e à criança que o que fosse falado no contato com o professor seria imediatamente comunicado a esta última. Tal procedimento visava manter a confiança das crianças no terapeuta, visto que muitas vezes elas o imaginavam como um "agente" da escola.

Um caso ilustrativo de mudança de postura do professor, no sentido de maior engajamento, ocorreu com uma professora de segunda série, cujo aluno vinha sendo atendido havia cerca de seis meses. Ao se iniciar o trabalho, realizava-se uma entrevista com a professora, na qual se esclareciam os objetivos da ludoterapia e a forma de condução do processo. Também foi realizada a entrevista de final de semestre, além de algumas conversas esporádicas nos intervalos deste período, sobre questões da família da criança. Certo dia, ao ser o aluno convidado para a sessão ludoterapêutica perante a professora, esta indagou, em tom estranho e provocativo:

"E aí? Quando é que você vai falar comigo sobre ele?"

A pergunta, emitida na frente da criança, causou mal-estar e despertou a sensação de menosprezo e descrédito em relação ao atendimento, além de uma certa cobrança por resultados. Foi marcada então uma nova entrevista para tratar do assunto, em dia e horário diferentes do destinado à ludoterapia. $\mathrm{Na}$ data combinada, a professora, ao ver o terapeuta, exclamou em tom de surpresa e espanto: "Você veio só para falar comigo?!!!", fato que causou a impressão de que ela não acreditava no compromisso assumido por parte do outro, nem que pudesse ser valorizada.

Retomando-se as informações relativas ao objetivo do atendimento, foi esclarecido o significado do comportamento da criança, afirmando-se a importância do trabalho do professor como aliado do processo terapêutico. A professora terminou por constatar que a criança apresentara melhora no desempenho acadêmico, passando a conseguir copiar as lições em sala. No final do ano, quando a criança deixou de comparecer à escola e a mãe mostrou-se avessa a conversar sobre o atendimento do filho, esta 
mesma professora ofereceu-se para mediar o contato, dizendo:

"Ela não entende o nosso trabalho". Nesse momento, percebeu-se quanto a intervenção passou a ter outro sentido para a professora, com repercussão sobre a criança.

Outro exemplo marcante refere-se a um aluno da sétima série que também foi encaminhado para atendimento com a queixa de agressividade, mas a princípio recusou-se a participar. Com 14 anos de idade, o garoto vinha comparecendo à escola com uma arma escondida sob a blusa, assustando e afligindo os professores com sua postura desafiadora. O atendimento ainda não havia se iniciado quando uma de suas professoras, conhecida por uma postura mais rígida em classe, encontrou-o na feira. Surpreendentemente, o garoto prontificou-se a carregar suas compras, oferta que foi aceita pela docente. Depois deste contato, tudo mudou na relação entre eles em sala de aula. Ele a presenteou com um pote de mel e ela redobrou a atenção para com ele, preocupando-se até mesmo em providenciar-lhe material escolar. Além disso, após algum incentivo de sua parte, ele aceitou participar da intervenção psicoterápica, sendo acompanhado desde então.

Não se pode deixar de mencionar a demanda de uma supervisão quinzenal por parte da coordenação da escola dirigida à coordenadora do projeto. Este trabalho, realizado fora do ambiente escolar durante o período de um semestre, representou importante espaço de escuta sobre as mais diversas dificuldades de manejo da agressividade na escola, oferecendo apoio e alguma orientação às educadoras.

Este trabalho de intervenção clínica preventiva ainda continua, mas agora no espaço institucional universitário de origem das autoras, para o qual os educadores e a coordenação da escola fazem o encaminhamento das crianças, em função da confiança e do intercâmbio consolidado com este projeto.

\section{CONCLUSÃO}

Considerando-se que a agressividade, como assinala Winnicott (1939/1987a, 1956/1987b), é uma reivindicação ao ambiente visando ao reconhecimento e retorno a um período de privação crítica para a retomada do desenvolvimento emocional, a escola não poderia deixar de vivenciar manifestações de comportamento agressivo. Ao oferecer um ambiente relativamente estável, com regras claras, a escola configura um espaço de confiabilidade, constância e segurança, muitas vezes ausente da história de vida de algumas crianças. Assim, elas depositam suas necessidades de atenção, afeto e firmeza nos educadores, esperançosas de contarem com parâmetros e limites que, geralmente, não foram estabelecidos pela família.

Os professores não se mostram indiferentes a essa demanda; ao contrário, cumprem papel ativo perante as crianças mais agressivas, alimentando-lhes a esperança de alcançar uma estabilidade interna. Evidências dessa postura podem ser encontradas na fala dos docentes, que assumem, apesar do desgaste, providências para o manejo da agressividade em sala de aula. Além disso, sustentam a crença em um modelo de relação professor-aluno ideal, cujos valores estão pautados na tolerância, compreensão, respeito e disponibilidade, anseios que devem ser transmitidos, de algum modo, na relação com as crianças.

$\mathrm{Na}$ experiência de atendimento preventivo a meninos agressivos no ambiente escolar, constata-se ainda quanto a intervenção psicológica produz ressonância na escola, mais especificamente na relação professor-aluno, ajudando o docente a suportar a manifestação agressiva em classe, pois ele pode vislumbrar importantes ganhos e sutis mudanças alcançadas no decorrer do trabalho clínico.

\section{REFERÊNCIAS}

Anser, M. A. C. I., Joly, M. C. R. A., \& Vendramini, C. M. M. (2003). Avaliação do conceito de violência no ambiente escolar: visão do professor. Psicologia: Teoria e Prática, 5(2), 67-81.

Aquino, J. G. (1999). Confrontos na sala de aula: uma leitura institucional da relação professor-aluno. São Paulo: Summus.

Batista, A. S., \& Pinto, R. M. (1999). Segurança nas escolas e burnout dos professores. Em W. Codo (Coord.), Educação: carinho e trabalho (pp. 312-332). Petrópolis: Vozes.

Camps, C. I. C. M., \& Vaisberg, T. M. J. A. (2003). Sofrimento na escola: uma nova abordagem do imaginário grupal "professores de segundo grau". Em F. F. Ambrosio \& T. M. J. A. Vaisberg (Orgs.), Trajetos do sofrimento: rupturas e (re)criações de sentido (pp. 114-120). São Paulo: Instituto de Psicologia, USP.

Candau, V. (1999). Escola e violência. Rio de Janeiro: DP\&A.

Carlotto, M. S., \& Palazzo, L. S. (2006). Síndrome de burnout e fatores associados: um estudo epidemiológico com professores. Cadernos de Saúde Pública, 22(5), 1017-1026.

Carlotto, M. S. (2002). A síndrome de burnout e o trabalho docente. Psicologia em Estudo, 7(1), 21-29.

Charlot, B., \& Émin, J. C. (Coord.). (1997). Violences à l'école. État des savoirs. Paris: Armand Colin.

Charlot, B. (2002). A violência na escola: como os sociólogos franceses abordam essa questão. Sociologias, 8, 432-443.

Collingridge, D. S. (2004). A phenomenological inquiry into teachers' experience of being hindered. Unpublished doctoral dissertation, Brigham Young University, Department of Psychology, Utah, USA. 
Debarbieux, E. (1998). Le professeur et le sauvageon: Violence à l'école, incivilité et postmodernité. Revue Française de Pédagogie, 123, 7-19.

Debarbieux, E. (1999). La violence en milieu scolaire - Le désordre des choses. Paris: ESF.

Freller, C. C. (1993). Crianças portadoras de queixa escolar: um enfoque winnicottiano. Dissertação de Mestrado não publicada, Instituto de Psicologia, Universidade de São Paulo, São Paulo.

Hastings, R. P., \& Bham, M. S. (2003). The relationship between student behavior patterns and teacher burnout. School Psychology International, 24(1), 115-127.

Katz, C. L. (1992). Agressive Children. In J. D. O'Brien, D. J. Pilowsky \& O. W. Lewis (Eds.), Psychotherapies with children and adolescents: Adapting the psychodynamic process. Washington: American Psychitric.

Kernberg, P. F., \& Chazan, S. E. (1993). Crianças com transtornos de comportamento - manual de psicoterapia. Porto Alegre: Artes Médicas.

Klein, M. (1927). Tendências criminais em crianças normais. Em Contribuições à Psicanálise (Vol. I, pp. 197-213). São Paulo: Mestre Jou 1970.

Kupfer, M. C. (1998). Violência da educação ou educação violenta? Em D. L. Levisky (Org.), Adolescência pelos caminhos da violência (pp. 129-137). São Paulo: Casa do Psicólogo.

Laterman, I. (2002). Incivilidade e autoridade no meio escolar. Em ANPED - Associação Nacional de Pós-Graduação em Educação (Org.), $25^{a}$ Reunião Anual ANPED -Educação: manifestos, lutas e utopias (pp. 01-19). Caxambu: Anped/UFSC.

Lopes, C. S. (2000). Violência e trabalho escolar. Teoria e Prática da Educação, 3(6), 91-113.

Meleiro, A. M. A. S. (2002). O stress do professor. Em M. E. N. Lipp (2002), O stress do professor (pp. 11-27). Campinas: Papirus.
Ristum, M., \& Bastos, A. C. S. (2004). Violência urbana: uma análise dos conceitos de professores do ensino fundamental. Ciência e Saúde Coletiva, 9(1), 225-239.

Royer, E. (2003). Condutas agressivas na escola: pesquisas, práticas exemplares e formação de professores. Em Unesco (Org.), Desafios e Alternativas: violência nas escolas, Brasília: Unesco.

Silva, M. E. P. (2006). Burnout: por que sofrem os professores? Estudos e Pesquisas em Psicologia, 6(1), 89-98.

Souza, M. A. (2001). Intervenção psicoterapêutica em meninos agressivos escolares como prevenção de comportamento transgressor futuro. Psicologia: Teoria e Prática, 3(2), 21-35.

Souza, M. A., Soldatelli, M. I. S., \& Lopes, A. R. (1997). Psicodinamismo familiar de crianças agressivas. Anais do $I$ Congresso de Psicologia Clínica do Mackenzie (pp. 61-64). São Paulo.

Tremblay, R. E. (2000). The development of aggressive behaviour during childhood: What have we learned in the past century? International Journal of Behavioral Development, 24,129-141.

Tricoli, V. A C. (2002) O papel do professor no manejo do stress do aluno. Em M. E. N. Lipp (Org.), O stress do professor (pp. 90106). Campinas: Papirus.

Winnicott, D. W. (1987a). Agressão. Em Privação e Delinqüência (pp. 89-96). São Paulo: Martins Fontes. (Original publicado em 1939).

Winnicott, D. W. (1987b). A tendência anti-social. Em Privação e Delinqüência (pp. 127-137). São Paulo: Martins Fontes. (Original publicado em 1956).

Recebido em 27/06/2006 Aceito em 12/01/2007

Endereço para correspondência : Maria Abigail de Souza. Av Professor Mello Moraes, 1721, bloco F, Cidade Universitária, CEP 05508-030, São Paulo-SP.E-mail: abigail@usp.br 